I then concluded that what the owner had thought to be a penis was nothing more than a very much hypertrophied clitoris.

To obtain the snapshot here reproduced the inferior commissure of the vulva had to be elevated to show the orifice situated beneath it. The enlarged clitoris protrudes from this opening, and can be seen in the photograph just in front of the man's index finger.

This mare, I was informed, is continually "horsing," and frequently during micturition a few drops of urine escape from the lower opening.

I have suggested that the mare should be operated on and have the piece of skin between the orifice and the vulva excised, clitorodectomy to be performed afterwards if necessary.

Case II.-An Indian mule, aged seven, height 12\%. Anyone on casually looking at this mule walking past, with her tail swinging, or even if one stood behind her with her tail held to one side, would at first sight say she was a gelding.

The vulva is simply a vertical slit, half to three quarters of an inch in length, and it is almost completely hidden under the prominence of the anus.

On several occasions I have taken photographs of her in the standing position with the tail held to one side, and in none of them is the vulva visible.

The labia are undeveloped, being composed of the ordinary thin skin similar to that of the perineum of the horse.

The clitoris is about the size of a pea.

This mule, which is a very docile animal, has no difficulty in urinating, and the congenital deformity in no way interferes with her work.

\title{
MULTIPLE LIPOMATA OF THE PERITONEUM OF THE OX.
}

\section{By A. M. TrotTer, M.R.C.V.S., Glasgow.}

MULTIPLE lipomata of the peritoneum of the ox are occasionally found on post-mortem examination. Their occurrence is interesting not only of itself but also because it is apt to be confounded with other conditions of much greater importance. For instance, it bears a close macroscopical resemblance to tuberculosis, actinomycosis, and the metastatic lesions of carcinoma.

On closer examination, however, even with the naked eye, the growths are seen to be largely composed of adipose tissue, and therefore distinguishable from other conditions. The following case is given as somewhat typical.

The point of interest in this case is that the uterus was absent, having evidently been surgically removed some considerable time previous to slaughter. The os uteri having remained patent, the peritoneal cavity was in direct communication with the vagina. Unfortunately it was impossible to ascertain whether the ovaries were in situ, as the carcase had been dressed for market prior to examination.

Some pathologists believe that lipomata are caused through 
irritation, and in this case it is certainly within the range of probability that some irritant gained access to the peritoneal cavity through the os uteri, or from some existing ovarian tissue.

The serous membrane of the peritoneal cavity, particularly on the left flank, was studded with nodules, isolated or grouped, white in colour, and varying in size from a rape seed to a walnut. They were attached to the serous membrane by long slender pedicles, and apparently did not involve the underlying tissue. The smaller nodules retracted on their own bases, and presented a round, flattened, sessile appearance, while the larger, owing to their greater size and weight, overhung, and showed in greater or less degree their mode of attachment. They were intersected by fissures, more or less deep, which gave some the appearance of several nodules springing from one pedicle, after the manner of a cauliflower.

After rigor mortis was complete, the majority of the nodules were soft, tough, non-elastic, somewhat translucent, and homogeneous, while the others were firm and slightly elastic, owing to the infiltration of fat in their tissues. The nodules in which the infiltration was excessive were rotund, and the intersecting fissures were more or less obliterated. Delicate blood-vessels ramified over the surface of many of the nodules. In some instances cysts had formed, the largest being of the size of a hazel-nut. Their surface was uneven, owing to the attachment of septa, which subdivided them in compartments. The limiting wall of these cysts was thin and transparent; their contents were watery in consistency, clear or slightly turbid in appearance, and alkaline in reaction, and on the addition of acetic acid a cloudy precipitate was thrown down.

The nodules on section were seen to be composed of white and somewhat translucent materials arranged alternately in wavy lines of unequal thickness. A few delicate blood-vessels were present. The cut surface was moist, Areas of fat were present in the tissues of all the larger nodules. The fat was deposited either as round masses or lines. In the early stages the line of demarcation was indefinite, but later it was sharply defined. The fat was normal in appearance, and similar in colour to ordinary adipose tissue.

Similar nodules were attached to the serous surface of the stomach, liver, spleen, kidney, fat, omentum, mesentery, intestines, and bladder.

Microscopical examination confirmed the opinion formed on macroscopical examination-that these nodules were composed largely of adipose tissue, and were, in fact, lipomata.

\section{NOTE ON THE OCCURRENCE OF "MARGINAL POINTS;" OR A NEW INTRACORPUSCULAR PARASITE, IN THE BLOOD OF CATTLE IN SOUTH AFRICA*}

By J. SpreulL, F.R.C.V.S., East Griqualand, South Africa.

THE following account of two cases of a newly recognised blood disease may prove of interest, although I regret that, in the absence of a post-mortem examination or any experimental inoculation work, it is necessarily very incomplete. 